Revista Tempos e Espaços em Educação, v. 5, p. 19-29 jul./dez. 2010

\title{
Do ateliê à Enciclopédia: a escola do homem de ciência
}

\author{
Eliane Mimesse \\ Luís Dário Sepulveda
}

\begin{abstract}
Resumo
Este artigo analisa a forma e a cultura da escola do douto. Visa entender o local de aprendizagem desse homem nos séculos XVI ao XIX. Estabeleceram-se três momentos de análise: o da investigação que teve início no barroco, quando o termo "homem de ciência" começou a ser difundido; a questão do método experimental como fruto do trabalho nos ateliês dos artesãos, que demonstraram que era possível o aprendizado sem o saber escolarizado; e a cultura do aprender-fazendo. Os principais autores utilizados para esclarecer esse processo foram Maravall (1997) por utilizar o termo "homem de ciência" como sinônimo de conhecedor da cultura dos clássicos; Rossi (1991) para entendermos o surgimento desse "homem" a partir do uso do método experimental, que foi o conflito entre o conhecimento prático e o livresco; Rugiu (1998) por relatar a formação do aprendiz italiano até esse atingir o grau de mestre e, Cunha (2000) quando abordou a aprendizagem de ofícios artesanais e manufatureiros no Brasil no período estudado. Conclui-se que, muito mais que entender a forma e a cultura escolar do "homem de ciência" esse estudo possibilitou uma investigação das práticas de formação desse sujeito.
\end{abstract}

Palavras-chave: história da ciência, método experimental, cultura escolar.

\section{From Atelier to the Encyclopedia: the science man school}

\begin{abstract}
This paper analyzes the form and the culture of the "douto" school. It aims to understand the place of learning of this man from XVI to XIX centuries. Three moments of analysis had been established: the inquiry that started in the baroque era, when the term "science man" started to be spread out; the experimental method question as fruit work of the craftsmen in ateliers, who had demonstrated that the learning without school knowing was possible; and also the culture of learn-making. The main authors used in the research to clarify this process were Maravall (1997) for using the term "science man" as a synonym of the classical culture expert; Rossi (1991) to understand the sprouting of this "man" from the use of the experimental method, that was the conflict between the practical knowledge and the theoretical; Rugiu (1998) for telling the formation of the Italian learner until he reaches his master degree and, Cunha (2000) when approached the artisan's learning in Brazil in the studied period. The results showed that more than understanding the form and the school culture of the "science man", this study brought an inquiry of the practices and the formation of this citizen.
\end{abstract}

Key-words: science history, experimental method, school culture. 
A escola do douto ou do "homem de ciência" foi fundamental para o ensino da chamada Ciência Moderna. O conhecimento científico da Enciclopédia em certo momento de sua formação saiu da Academia e visitou as oficinas dos mestres artesãos para entender como ocorria a aprendizagem, a construção do método e a "transferência do conhecimento" entre mestre e aprendiz. Conforme Oliveira (2010, p.89), é recorrente que "o homem culto abandone seu tradicional desdém frente aos conhecimentos vulgares e vá às oficinas e fábricas para procurar aprender com os artesãos acerca dos detalhes de seus afazeres".

Assim sendo, este estudo verificou algumas das práticas adotadas entre os séculos XVI e XIX, analisou como essas práticas se organizaram na execução de suas tarefas, além de observar e registrar os detalhes implícitos concernentes à precisão dos atos e a sua alta complexidade. Para tanto, se pode indicar como exemplos desse movimento os processos das manufaturas dos canhões e das caravelas; o domínio militar e civil das várias técnicas de mineração, neste caso principalmente no manuseio da pólvora; o detalhamento e as minúcias no desenvolvimento de objetos de madeira, decorrente da ostentação inerente ao estilo Barroco.

A trama tecida pela escola do "homem de ciência" começou a ser forjada na tensão entre as "artes mecânicas" e as "artes liberais", sendo que as "artes mecânicas" revelaram-se de modo estritamente social. O homem não letrado estava fadado ao uso de suas energias físicas no emprego de tarefas manuais, na manufatura de seus produtos. Esse sujeito, por assumir o papel de executor nos trabalhos manuais, deu margem à que determinados grupos sociais apresentassem resistências a essa modalidade de trabalho, e a todas as outras atividades relacionadas diretamente a ele. $\mathrm{O}$ homem executor das tarefas manuais não contava com a liberdade, logo ele estava na contramão das "artes liberais".

No período Barroco as "artes mecânicas" conseguiram atingir um novo reconhecimento na reformulação do saber e, sobretudo no ensino. Essa ação tomou corpo quando da organização e do aprimoramento das técnicas. Portanto, as "artes mecânicas" assumiram e transformaram as ações cotidianas do "homem do agir", essas artes conduziram esse sujeito em questão ao contado com a natureza e às novas conquistas.

De acordo com Oliveira (2010), Francis Bacon tornou-se um dos representantes desse pensamento, a partir do momento em que valorizou as virtudes da natureza e a beleza da experimentação, em oposição à exaltação das "artes liberais", ao conhecimento livresco e, as verdades dos mestres. Dessa tensão, surgiu paulatinamente a implementação de uma educação literária e retórica, que apresentasse as práticas úteis ao cotidiano e que, a partir desse momento, deveriam formar um novo tipo de homem. $\mathrm{O}$ aprender-fazendo gerou grandes interesses na sociedade, ocorreu, consequentemente, uma demanda maior na procura dos aprendizes por ateliês.

Verificou-se que com o crescimento da inventividade e da criatividade na confecção de instrumentos, muitas das verdades até então reconhecidas tornaram-se falácias. As "artes mecânicas" geraram um conhecimento que pôde ser apreendido e valorizado, estabeleceu seu reconhecimento na sociedade, o do simples saber-fazer.

O deslocamento do ateliê à enciclopédia será abordado neste estudo bibliográfico segundo o reconhecimento do "homem de ciência", que tomou distância dos livros e buscou na natureza as práticas para suas verdades.

Esse caminhar do "homem de ciência" aos ateliês favoreceu, no campo das Ciências Naturais, o fortalecimento do método como prática educativa e a matematização das leis da natureza em leis científicas. Esses múltiplos olhares foram articulados entre os elos do homem conhecedor da cultura dos clássicos, do método abordado pela experimentação, da ação dos aprendizes e da prática desenvolvida na manufatura da agroindústria no Brasil.

\section{A forma e a cultura do "homem de ciência"}

O "homem de ciência" é um termo que começou a ser cunhado na transição do renascimento ao barroco. O renascimento foi um período com baixo espírito crítico. Foi na época barroca que o termo 
se consolidou, pois a cultura desenvolvida nesses anos teve como ponto central o enaltecimento das características urbanas, dirigidas, massivas e conservadoras, todas foram frutos da articulação do regime político em vigor, o absolutismo monárquico.

O Barroco não é resultado de um ideal que a nostalgia do passado sugere aos burgueses, mas de um conjunto de recursos, psicologicamente estudados e manejados com habilidade, que visa imprimir as linhas de uma mentalidade, de acordo com os interesses dos grupos poderosos, nas camadas da população urbana, e, chegado o momento, da população rural. (MARAVALL, 1997, p.135)

Foi nessa população urbana que a ciência do século XVII começou a se desenvolver. Essa mesma ciência foi questionada por Rossi (1989), no sentido de se verificar a possibilidade de que um homem soubesse algo e conhecesse os efeitos naturais do que soubesse sem ter, obrigatoriamente, efetuado determinadas leituras específicas, dos compêndios em latim difundidos entre os estudiosos, escritos por filósofos renomados.

Rossi (1989) verificou que o "homem de ciência" assumiu uma atitude moderna, a partir do momento em que passou a rejeitar inconscientemente as obras clássicas e a supervalorizar as "artes liberas". Esse sujeito passou a fazer uso de seu raciocínio, tornou desta forma, a razão um instrumento de investigação. Esses indivíduos e seus novos raciocínios apresentaram-se na contramão do processo erradicado na sociedade, esse por sua vez, referia-se a sabedoria como sendo dos "doutores de memória", aqueles sujeitos que demonstravam todos seus saberes segundo a memorização de conceitos e narrativas, como o método de memorização desenvolvido e difundido por Pedro de Ravena, no século XVII. O livre pensar, também conhecido como a liberdade das ideias, marcou esse período, em função do desconhecimento de alguns pré-requisitos necessários, até então, à aprendizagem como o latim, as matemáticas - aritmética, álgebra, geometria - e a leitura de livros. Portanto, o conhecimento, nesse processo de reflexão, passou a ser produzido com a ausência de tais ferramentas teóricas institucionalizadas.

A magia ou a alquimia - em alguns momentos históricos também chamada de bruxaria - pôde representar o que era o não institucionalizado nesse momento. Essa alquimia deixou uma herança, pois seu desenvolvimento possibilitou o que mais tarde tornou-se o "método científico". O alquimista ao desenvolver suas fórmulas estava simultaneamente criando um determinado método de trabalho, em sua escrita ou simplesmente na memorização dos componentes, bem como tudo o que por ele foi criado, poderia desse modo ser repetido por outro alquimista.

Descartes no século XVII abandonou seus preceptores de formação escolástica e de edificação inquestionável do conhecimento, que enfatizavam o exercício da memorização e a repetição de verdades irrefutáveis. Encontrou nas matemáticas uma aliada aos questionamentos acerca das verdades escolásticas e, por meio delas, evidenciou seu raciocínio filosófico e científico. No prefácio de sua obra: A Dióptrica, Os Meteoros e A Geometria, encontramos o "Discurso sobre o Método". Esse método possibilitava um exame livre em prol do racionalismo.

Os sentidos foram questionados por Descartes, e a razão assumiu outras formas de compreensão, como uma revelação pura e diferente. A evidência, a análise e a síntese compuseram a base do método cartesiano.

Nesse movimento de descobertas deparamo-nos com o "homem de ciência", que entendia o método como essencial ao seu desenvolvimento, para ampliar sua visão de mundo e para poder viver em uma sociedade em transformação.

Galileu Galilei, contemporâneo de Descartes, ampliou essa abordagem da investigação científica desse "homem de ciência", ao corroborar com o método mediante o uso da experiência, em sua análise dos fenômenos naturais e de suas ideias do Universo. Tal qual o negociante em suas transações mercantis, onde o saber conduzia a um "homem do agir", esse homem circulava no seu meio social com suas ferramentas específicas. O modelo pragmático encontrou na medicina uma grande parceira, por 
aperfeiçoar o ensino de seus métodos e ainda alterar o estado de saúde dos homens.

Rossi (1989) acreditava que o "conhecer e fazer" estavam associados à transformação do mundo. Deste modo, os cientistas buscavam nos acontecimentos da natureza suas explicações, surgiram assim os primeiros "conceitos e métodos" da Ciência Física, mais especificamente de um ramo da Física, denominado de mecânica. O "homem de ciência", segundo os comentários de Hilsdorf (1998) observava a natureza e identificava-a em um mecanicismo no mundo. A natureza teria a função de ser como um modelo para a compreensão do conhecimento humano. Foi nesse momento que se identificou o alvorecer do processo de abandono da ideia renascentista de o mundo ser construído à medida do homem.

As "artes mecânicas" inauguraram um novo momento na formação do "homem de ciência". Ao negar os conhecimentos dos doutos, o "homem de ciência" constatou que ele poderia alterar e manipular a realidade como conhecimento. O que essa ação representou a esse "homem de ciência"?. Esse sujeito passou a conhecer as verdades a partir do seu intelecto ou dos recursos que as "artes mecânicas" lhe forneceram. Dois exemplos para ilustrar essa argumentação podem ser o de Galileu Galilei e a criação de seu telescópio e de René Descartes com a publicação da obra o Discurso do Método. De acordo com Rossi (1991) o conhecimento a cada momento será mais sistematizado, repleto de:

[...] métodos, procedimentos da linguagem e da técnica. Devem converter-se em objeto de reflexão e estudo: a experiência errata dos mecânicos, o desprezo daqueles que usam as mãos para modificar a natureza, deve subtrair-se ao azar e ao veneno da influência de magos e alquimistas, deve dar lugar a um corpo orgânico e sistemático de conhecimentos. (ROSSI, 1991, p.329)

Em uma sociedade estruturada segundo as representações, as pessoas que desenvolviam suas atividades com as mãos ou com sua prática, eram deslocadas e discriminadas pelo grupo social dominante. Esses indivíduos estavam fadados à marginalização. Somente os iniciados poderiam expressar as ações consideradas "clássicas", essas estavam restritas a um grupo de eleitos, que eram os detentores dos conteúdos e dos segredos e, principalmente, de como decifrá-los. Contudo, havia um grande esforço por parte da população na busca de locais de aprendizagem; os manuais começaram a circular em vários idiomas. Segundo Rossi (1991), desenvolveu-se uma nova imagem de um saber acessível ao sujeito interessado, renegou-se a necessidade de vivenciar uma iniciação nos moldes religiosos, nem tampouco era necessário ser um eleito; o acesso à verdade não se fazia por meios complexos, mas através de uma linguagem clara e simples, ou seja, pelo método experimental; e qualquer indivíduo interessado no que ocorria poderia ter acesso a verdade científica, foco diametralmente oposto a questão perpetuada segundo as revelações divinas.

É relevante verificar como ocorreu esse acesso do homem à verdade científica e, quais as alterações sofridas pela aprendizagem após o surgimento do método experimental, bem como o "homem de ciência" obteve seu ingresso aos ateliês. Essas questões podem ser levantadas para refletirmos sobre a dificuldade na aceitação do novo método durante esse tempo histórico.

Mas o que realmente importa e marca uma revolução na postura do cientista é a confiança de Galileu num instrumento nascido no ambiente dos artesãos, aperfeiçoado apenas "pela prática", parcialmente acolhido pelos militares, mas ignorado, quando não desprezado, pela ciência oficial. (ROSSI, 1989, p.100)

O conflito entre o conhecimento prático e o conhecimento livresco estava pairando no ar. Nos escritos de Rossi (1989) verificou-se que Bacon foi um dos grandes defensores da necessidade de se estudar a história das técnicas artesanais. A 
justificativa para tanto se apoiava na demonstração dos objetos em movimento, que conduziam as ações mais rapidamente à prática. Entre os experimentos e estudos baconianos podemos citar a agricultura, a culinária, a química, o tingimento, as manufaturas de vidro, o esmalte, o açúcar, a pólvora e o papel.

Portanto, o método experimental caracterizou a ciência moderna. Rossi (1989) ainda ratificou que o surgimento desse método não derivou dos debates filosóficos. Foram as práticas dos artesãos renascentistas, em conjunto com as observações dos navegadores que aportaram nas Américas, mais as ações concretas dos trabalhadores na construção dos fortes militares, na extração e fundição de metais, na fabricação de fogos de artifícios, de telescópios e de bombas hidráulicas que contribuíram para sua difusão. Todas essas práticas simultaneamente possibilitaram o surgimento e o reconhecimento desse método e de alguns manuais específicos.

$\mathrm{Na}$ tentativa de melhor compreender o conflito entre o conhecimento prático e o livresco, recorrer-se-á aos trabalhos de Rugiu na Itália e de Cunha no Brasil. Rugiu (1998) trouxe a valorização da pedagogia do aprender-fazendo, de várias maneiras. Primeiramente, identificou antes do século XII na Itália, o uso do termo: scholae que poderia ser entendido como as associações de ofício, entre eles pescadores, açougueiros, sapateiros, carpinteiros e hortelãos. Essas associações apresentavam uma preocupação coletiva em preservar a formação dos seus continuadores, de seu patrimônio cultural e pedagógico mediante um ritual particular de técnicas de transmissão.

Nos mosteiros a formação profissional e técnica, voltada ao clero se caracterizou no aprendizado pela memória, onde o ofício divino era recitar os ensinamentos e seus cantos. De acordo com Rugiu (1998) a vida nos mosteiros passou a ditar normas na sociedade burguesa por ser organizada e racionalizada. Existia no interior dessas instituições uma divisão técnica e social do trabalho, um modelo formativo até então desconhecido. $\mathrm{O}$ autor acreditava que o convívio do Trívio - gramática retórica e lógica - e do Quadrívio - matemática, geometria, astrono- mia e música- na prática cotidiana dos sacerdotes e clérigos e, a ação concreta existente na prática dos artesãos, antecipou a futura bifurcação entre formação nas "artes liberais" das escolas ou nas "artes mecânicas" das oficinas. Pode-se explicar ainda a que:

[...] entre Artes mecânicas das oficinas e Artes liberais das universidades ou das escolas, no final das contas, existe afinidade substancial: a educação em ambos os casos era dada principalmente pelo aprendizado de uma traditio feita de conhecimentos mais habilidades profissionais específicas, e pelas atitudes adequadas da personalidade, seja que ela dissesse respeito às regras projetuais e operativas e à fundamental ideologia do artífice, ou que dissesse respeito àquelas regras intelectuais do estudante e do professor. (RUGIU, 1998, p.31)

$\mathrm{O}$ artesão no mosteiro era parte de um projeto de alta sustentação. Muitas vezes isolado e fechado, o mosteiro contava com a formação de vários gêneros, dos pintores aos caldeireiros, aos cinzeleiros. De certo modo, os artesãos modificaram a rotina nos mosteiros, por terem conservado, não só as artes dos clássicos, mas também, por terem aprimorado as atividades materiais. Mas, Rugiu (1998) considerava que seria impossível ensinar aos artesãos com a mesma didática dos ensinamentos eclesiásticos, por que:

Os operários ocupavam-se exclusivamente de artes mecânicas e, portanto, encontravam-se em baixo na escala social. A escola na qual aprendiam suas técnicas era aquela da prática: isto é, consistia em um tirocínio para aqueles que possuíam já uma habilidade e conheciam os segredos do ofício. Os aprendizes, em essência, aprendiam fazendo. (RUGIU, 1998, p.19) 
Além dos muros dos mosteiros, a forte ascensão da burguesia cidadã e de sua visão sobre a essência da atividade humana, transformou as atividades liberais dos mestres das universidades e as atividades mecânicas dos mestres artesãos, em mercadorias, e deste modo, acessível a todos da comunidade. Rugiu (1998) afirmou que não só se mercantilizavam objetos, mas também as ideias e a própria atividade de transmissão de ideias e de comportamentos, a atividade pedagógica-didática tornou o ensinante em um artesão.

Contudo, eram nas Corporações que se guardavam os mistérios de todas as formas pedagógico-didáticas. Foi a escassa circulação, e em muitos casos, a própria ausência de manuais ou textos escolares escritos, até o final do século XVII, que justificaram o modo como os conteúdos eram transmitidos. Deve-se levar em conta, além desses itens, a inexistência de uma plena alfabetização por parte dos trabalhadores. O aprendizado, portanto, ocorria através da transmissão dos "segredos" de cada atividade, nas "artes liberais" por: escute as minhas palauras e nas "artes mecânicas" por: olhe como faço. Portanto, as Corporações conseguiram desenvolver a formação de seus aprendizes através da tradição oral ou intuitivo-gestual dos mestres. Como exemplo pode-se citar a ação dos alfaiates de coletes, ou dos construtores de castelos e catedrais.

Mas, como ocorreu o processo de aprendizagem do jovem aprendiz?. Nada sabemos, para Rugiu (1998) a didática interna que disseminou esses conhecimentos não foi ainda explicitada. O autor buscou nas Corporações os indícios de como seria essa aprendizagem. Nessas Corporações o mestre desenvolvia suas atividades com total liberdade, muitas vezes a casa do próprio mestre servia de abrigo ao iniciante aprendiz, mediante um contrato.

Quando o mestre considerava que o aprendiz estava quase preparado para exercer suas habilidades autonomamente, ou receber o título de magister artis, este era colocado a trabalhar com os mais experientes, na função de mestre adjunto ou sub-mestre. Essa ideia de colocar o aprendiz junto a outros mais experientes está no fato do mestre ter receio de que o aprendiz pudesse descobrir outros segredos de sua futura formação. É bom lembrar que, o contrato firmado pelo aprendiz alertava que o trabalho não ocorria só na atividade de oficina, mas também no clima e nas experiências da comunidade doméstica na qual era hospedado, pagando ou não. Era uma formação além das oficinas.

Quando estava na casa do mestre e depois na oficina, havia uma série de atos que advertiam o rapaz de quão importante seria o passo cumprido dentro do contrato estipulado, e de qualquer maneira, como seria mudada efetivamente a sua condição. Conhecia seus novos familiares, com os quais tinha dividido a mesa, pelos quais seria vestido e acudido; conhecia os seus pares por idade e por condição (...) Portanto, não era somente, a família do mestre ou a oficina com os seus operários e trabalhadores a desenvolver uma ação educativa e de integração, fundamental no processo de socialização, mas também o era o grupo de adolescentes e jovens no qual se inseria. (RUGIU, 1998, p.41)

Caso o mestre não cumprisse com o subscrito, ele deveria pagar uma multa. Era também esse mestre encarregado de fornecer as primeiras ferramentas ao aprendiz, para que ele pudesse trabalhar sozinho ou com outros mestres. Nas Corporações mais importantes, o aspirante deveria gratificar seus mestres. A relação entre o aprendiz e o mestre, era de socialização do comportamento.

Era proibido jogar cartas e dados na oficina, proibido permanecer ali dentro depois do fechamento noturno (também para evitar que os aprendizes e trabalhadores desenvolvessem por conta própria trabalhos sem o conhecimento do mestre ou danificassem materiais e instrumentos), proibido permanecer nos arredores da oficina (que lembra 
muito a proibição em tempos mais próximos de ficar fora da escola fazendo alvoroço e importunando as meninas), proibido acender fogo nos locais de trabalho. (RUGIU, 1998, p.49)

A essa socialização dos comportamentos, atribuiu-se ao aprendiz certas obrigações, como a de limpar e zelar pelo ambiente de trabalho. Nesse processo ocorreu o surgimento de uma divisão do trabalho, de modo a imprimir-lhe um novo ritmo, as horas canônicas não mais cadenciavam os afazeres e sim, as próprias exigências de trabalho. O sol como padrão de produção nas oficinas foi substituído, a Corporação estabeleceu uma medida profissional que se tornou o tempo urbano expresso pelas sinetas das oficinas. Essas Corporações eram as organizações das oficinas, oficinas artesãs e as lojas dos mercadores.

No século XVII a aprendizagem na Itália ocorreu com a ausência da escrita ou de ligações conceituais-operativas. O aprendiz não aprendia mediante o estudo de textos, o conhecimento ocorria por via oral-prática, sendo deste modo desenvolvido pela tradição oral e pela prática do mestre.

No Brasil os estudos de Cunha (2000) procuraram reconstituir os processos de aprendizagem do trabalho manufatureiro na agroindústria açucareira, nos colégios dos jesuítas, na mineração, nos arsenais de marinha e no artesanato urbano. $\mathrm{O}$ autor focou certa preocupação com o chamado trabalho manual, nos períodos entre a instituição da colonização e a estabilização do modus operanti do império.

A escola de ensino manufatureiro surgiu com a chegada da família real em solo brasileiro. Cunha (2000) escreveu que a aprendizagem sistemática de ofícios não assumiu durante a época colonial a forma escolar. Somente no período de transição para a formação do Estado nacional, durante o início do século XIX, com a estada da família real, que se criou a primeira escola para o ensino de ofícios manufatureiros.

A aprendizagem de ofícios nos engenhos não seguia padrões ou normas pré-estabelecidas. Os aprendizes não contavam com tarefas especiais na sua formação. De acordo com Cunha (2000) os mestres e contramestres eram deslocados de uma colônia à outra no início da implantação da agroindústria açucareira. A aprendizagem dos escravos e dos homens livres ocorria nos locais de seu próprio trabalho. O critério utilizado na seleção dos que iriam aprender era a disposição que este indivíduo apresentava, em termos técnicos, seria a força, a habilidade e a atenção; em termos sociais a lealdade ao senhor e ao seu capital, como na forma de efetuar as instalações, de cuidar de seus instrumentos de trabalho e da matéria-prima, como de mercadorias e a conservação de si próprio, nesse caso se escravo cativo.

Em Portugal a aprendizagem dos ofícios ocorria nos colégios e nas residências dos jesuítas. Esses clérigos trouxeram da Europa alguns artesãos, os chamados irmãos oficiais, para ensinar os seus misteres aos escravos e homens livres, devido a escassez de mão-de-obra qualificada em solo colonial.

Foi intensa a atividade dos jesuítas no ensino de ofícios nas reduções guaranis (...) A produção foi organizada de forma autárquica, desenvolvendo-se a tecelagem, a construção de edifícios, embarcações, ferramentas, instrumentos musicais, sinos, relógios, armas de fogo, pólvora, cerâmica, corantes e remédios. (CUNHA, 2000, p. 34)

Quando da descoberta do ouro em Minas Gerais ocorreu a criação dos ofícios na mineração. Os aprendizes para o ofício da mineração tinham um período entre quatro e seis anos para o aprendizado pleno. Após esse período o sujeito devidamente habilitado receberia um prêmio em dinheiro. Dentre os ofícios na mineração o que tomou maior relevância foi o da ourivesaria, porque a Coroa Portuguesa mantinha incentivo ao desenvolvimento desta prática, tendo em mente a necessidade do recolhimento dos impostos. No século XVIII, como relatou Cunha (2000) o ouro assumiu caráter de relevância extrema, a tal ponto que se cogitou o ensino sistemático da mineração. 
Constatou-se que no Liceu de Curitiba, na então Província do Paraná, a disciplina de mineralogia esteve indicada no currículo desta escola secundária pública, em fins do século XIX. Mas, o contexto neste caso era diferenciado, não houve descoberta de ouro em larga escala nesta localidade, mas em contraponto existiu o imperioso incentivo e apoio do Presidente da Província em enfatizar e desenvolver o ensino. Segundo Sepulveda (2002) essa mobilização do Presidente da Província encontrou ressonância nas salas do Liceu, com a instalação do chamado "gabinete". Uma sala de aula específica para o aprendizado da Física experimental. Entretanto, a prática do aprender fazendo ganhou outros caminhos, as ações estabelecidas nesse local estavam condicionadas a simples contemplação das experiências e de suas verdades. $\mathrm{O}$ aprendiz-aluno não participava da demonstração da experiência, tal tarefa ficava restrita ao detentor do saber, o professor. Esse era o indício da perpetuação das práticas escolásticas. Assim, a Física experimental, tradicionalmente associada às aplicações práticas, perdeu terreno para a chamada Física teórica embasada na matemática.

No Rio de Janeiro em meados do século XVIII, o comércio cresceu e a necessidade de expansão levou ao crescimento do contingente da marinha real, principalmente na fiscalização das costas brasileiras, a fim de evitar a pirataria. Deste modo, foram criadas as escolas de aprendizes marinheiros. Os alunos que frequentaram essas escolas eram recrutados através de patrulhas armadas, em seguida eram levados aos arsenais, para - ao contrário das cidades - pudessem aprender e praticar seus ofícios sem quaisquer tipos de regulamentação ou exames.

Com o crescimento da população no território colonial, surgiu com o passar dos tempos, uma maior necessidade em ampliar o contingente de novos artesãos. Cunha (2000) comparou a formação dos novos artesãos ocorrida no solo brasileiro com a organização do artesanato urbano lisboeta. $\mathrm{Na}$ capital portuguesa os aprendizes eram registrados na Câmara Municipal e, quando estivessem prontos para exercer o ofício, o mestre encaminhava-os para um juiz de ofícios que efetuava sua matriculava como oficial. Após certo período, ele era submetido ao exame. Cunha (2000, p. 45) esclarece esta ação com um exemplo do oficial confeiteiro, que em seu ofício deveria ter o conhecimento de cobrir frutas, "fizesse açúcar queimado e respondesse a várias perguntas sobre a maneira de se fazer doce". O exame ao qual o oficial se prestava nos mostra, que ele deveria ter um conhecimento teórico e prático do ofício.

No período imperial no Brasil os arsenais militares eram os grandes representantes da herança deixada pelo período colonial. Nesses estabelecimentos a manutenção da aprendizagem persistiu. Com a proclamação da Independência, os arsenais militares cresceram nas suas oficinas existiam indivíduos de idades variadas aprendendo ofícios artesanais e manufatureiros. Os futuros aprendizes eram recrutados com a faixa etária estabelecida entre os 8 e os 12 anos. O método utilizado na formação desses militares mirins era o do ensino mútuo ou método Lancaster, a aprendizagem desses aprendizes era composta por aulas de desenho e das Primeira Letras, que seria o conhecimento básico da leitura, da escrita e da matemática. Aos 21 anos de idade ocorria o término do período de aprendizagem, os aprendizes:

[...] recebiam certificado de mestre numa especialidade e eram contratados como operários efetivos, passando a receber soldo. As atividades dos aprendizes eram controladas de perto por um pedagogo (de preferência chefe de família ou sacerdote maior de 40 anos), auxiliado por um guarda e dois serventes para cada grupo de cinqüenta alunos. As penas previstas para as infrações disciplinares eram bastante graves: "diminuição da comida", prisão ou "posturas físicas", "segundo sua idade e robustez". No limite, previa-se a expulsão do estabelecimento. (CUNHA, 2000, p. 110)

A rotina no Arsenal de Guerra do Rio de Janeiro no século XIX demonstrava-se como de intensa 
atividade e complexidade, de acordo com o artigo normativo:

[...] os Aprendizes Menores deverão estar acordados ao romper do dia; depois de lavados e vestidos entrarão em forma de revista; e desta marcharão por esquadras para as Aulas ou Oficinas, terão meia hora de descanso para almoçarem; jantarão à meia hora depois do meio dia, e as duas regressarão para as Aulas ou Oficinas; depois da ceia se recolherão aos dormitórios, onde serão entretidos uma hora na instrução da doutrina e rezas cristã. (CUNHA, 2000, p.110)

Mas, não foram apenas os aprendizes menores do Arsenal de Guerra que deveriam conviver com regras rígidas. Existiam Casas de Educandos Artífices ou entidades filantrópicas, que eram mantidas integralmente pelo Estado. Essas casas somaram um número total de dez e eram localizadas nas capitais das províncias. A casa montada na Província do Pará foi a primeira a ser instalada no Brasil e serviu de modelo às posteriores. Nessa casa, conforme Cunha (2000) os aprendizes recebiam os ensinamentos de carpinteiro de machado, calafate, marceneiro, pedreiro, ferreiro, serralheiro, canteiro, tanoeiro, funileiro e sapateiro. As casas dos educandos artífices ensinavam além dos ofícios específicos, as Primeiras Letras, a arte da escultura, o desenho, a aritmética, noções gerais de álgebra, geometria e mecânica aplicada às artes.

Na cidade do Rio de Janeiro, mediante regulamentação da Instrução Pública, foi estipulado que o governo deveria criar asilos para os menores. Mas, a criação desses asilos efetivou-se somente duas décadas depois, quando ocorreu a inauguração do Asilo de Menores Desvalidos. Local que receberia os alunos com problemas físicos, compreendendo a faixa etária entre 6 e 12 anos, esses alunos teriam estudos elementares ou, poderiam optar pela aprendizagem de um ofício.

O ensino no início do processo de expansão, urbanização e industrialização, fizeram com que a população procurasse outros meios de formação para seus filhos.

O ensino compreendia três partes. A primeira era a instrução primária. A segunda era constituída das seguintes disciplinas: álgebra elementar, geometria plana e mecânica aplicada às artes; escultura e desenho; música vocal e instrumental. A terceira parte era constituída dos ofícios ensinados no estabelecimento: tipografia, encadernação, alfaiataria, carpintaria, marcenaria, tornearia, entalhe, funilaria, ferraria, serralheria, coureraria e sapataria. O ensino dos ofícios era ministrado por mestres contratados para dirigirem cada uma das oficinas existentes. (CUNHA, 2000, p. 116)

Nesse ínterim, foram criadas as escolas para deficientes visuais e a escola de surdos-mudos, ambas na capital imperial. Após a promulgação da Lei de abolição dos escravos, os libertos ganharam uma escola profissional, denominada como de Escola Mista da Imperial Quinta da Boa Vista. Essa Escola manteve três cursos:

[...] o curso de ciências e letras tinha um currículo que o identificava com os do ensino secundário: instrução religiosa, português, francês, inglês, matemáticas elementares, história do Brasil, geografia, história geral, noções de física, noções de química, botânica, zoologia, mineralogia. O curso de artes compreendia as seguintes matérias: ginástica, música, desenho geométrico, desenho de ornatos, flores e animais, desenho de arquitetura e regras de construção. Os aprendizes artífices se exercitavam, também, nas oficinas de carpintaria, torno de metais e madeira, ferraria e serralheria, funilaria. (CUNHA, 2000, p. 118). 
Cunha (2000) fez referência a Academia de Belas-Artes e ao curso de telégrafo existente nesta instituição de ensino. Segundo esse autor a admissão do candidato às aulas dessa Academia dependia de o candidato saber os rudimentos mínimos da aprendizagem: ler, escrever e contar as quatro espécies de números inteiros. Nessa instituição os alunos eram divididos em dois grupos: os artistas que faziam o estudo das belas-artes e os artífices que se aprofundavam no estudo das artes mecânicas. No final do século XIX foi criado o curso de telegrafia pública, contando com um número razoável de sujeitos. A listagem das matérias teóricas eram as seguintes:

[...] aritmética; princípios gerais de álgebra e geometria; princípios gerais de física e de química aplicadas às leis e teoria da eletricidade; princípios gerais de magnetismo e do eletromagnetismo em suas relações com a telegrafia; desenho; elementos de mecânica aplicada a construção de aparelhos; As matérias práticas compreendiam escrita telegráfica; manipulação de aparelhos; arranjos de baterias; processo de verificação dos estados das linhas; maneira de assentar aparelhos; prática de oficina; escrituração. (CUNHA, 2000, p.121)

Também nesse século XIX foi criado o Liceu de Artes e Ofícios. Essa escola surgiu com a concepção de escola do povo, em contraponto a Academia que foi criada como escola superior. Os cursos oferecidos pelo Liceu eram vetados aos escravos, mas em contraponto abertos aos demais, eram cursos gratuitos e noturnos, o que facilitava o acesso dos homens trabalhadores. As matérias que compunham o currículo do Liceu de Artes e Ofícios eram:

[...] Ciências Aplicadas - aritmética, álgebra (até equação do $2^{\circ}$ grau), geometria plana e no espaço, descritiva e estereotomia, física aplicada, química aplicada e mecânica aplicada; Artes - desenho de figura (corpo humano), desenho geométrico, inclusive as três ordens clássicas; desenho de ornatos, de flores e de animais; desenho de máquinas, desenho de arquitetura civil e regras de construção; desenho de arquitetura e regras de construção escultura de ornatos e arte cerâmica, estatuária, gravura e talho doce, água-forte, xilografia; e pintura. (CUNHA, 2000, p.124)

Por fim, os conteúdos ensinados na Academia voltados ao conhecimento escolástico encontraram um grande espaço para a sua manutenção e seu desenvolvimento. Os conhecimentos expressos pela Academia foram moldados exclusivamente pela organização e racionalidade. Nas oficinas dos mestres artesãos, o conhecimento era forjado na prática da experimentação e da manipulação de artefatos. Era a ação do aprender-fazendo que envolvia a tentativa do acerto e do erro. $\mathrm{O}$ douto e o aprendiz se construíram nessa tensão entre os conhecimentos, baseados na investigação científica por um lado e, por outro pelo exercício da racionalidade filosófica acerca dos saberes e das verdades.

\section{Considerações finais}

Maravall (1997) nos apresentou o contexto no qual o "homem de ciência" foi forjado no período do barroco. Rossi (1991) ao identificar o método experimental como gérmen dos ateliês renascentistas, mostrou que o "homem de ciência" poderia manipular e alterar seu meio, mediante sua racionalidade. Para esse autor os doutos cederam lugar aos sujeitos que tivessem o domínio do método. $\mathrm{O}$ valor relevante do papel da experiência vinculou o homem ao mundo real, por meio das leis físicas que poderiam ser comprovadas.

Rugiu (1998) nos ajudou a analisar como ocorria a formação do aprendiz e de sua cultura formativa. $\mathrm{Na}$ verdade, mostrou que o aprender-fazendo era permanente, tanto para o aprendiz italiano quanto para o brasileiro. Cunha (2000) apresentou vários 
questionamentos, quanto à forma e cultura escolar no território brasileiro.

Foi desse processo que nasceu o método experimental, e o homem que buscou na natureza suas explicações e identificou nas leis da Física as representações do saber universal, do conhecimento, mediante a matematização de suas leis.

Essa imbricação entre Ateliê e Enciclopédia aguçou a reflexão dos dois modelos de sociedade que surgiram neste contexto. Por um lado, temos a racionalidade referenciada nas matemáticas, que caracterizaram a escola francesa, e de outro, o pragmatismo inspirado na experimentação da escola inglesa, presente na revolução industrial. Ambos os modelos marcaram a astúcia científica da ciência moderna, que de certo modo, resgataram as práticas de outrora presentes na atualidade, nas discussões sobre a formação e aprendizagem dos alunos, referimo-nos ao ofício de professor e ao ofício de aluno.

\section{Referências Bibliográficas}

ALMEIDA, José R. P. de. História da Instrução

Pública no Brasil, 1500 a 1889. São Paulo: EDUC; Brasília, DF: INEP/MEC, 1989.
CUNHA, Luiz A. O Ensino de Ofícios artesanais e Manufatureiros no Brasil Escravocrata. São Paulo: Editora da UNESP, Brasília/DF: FLACSO, 2000.

HILSDORF, Maria L. S. Pensando a Educação nos Tempos Modernos. São Paulo: EDUSP, 1998.

MARAVALL, José A. A Cultura do Barroco: Análise de uma Estrutura Histórica. São Paulo: Editora da UNESP, 1997.

OLIVEIRA, Bernardo J. de. Francis Bacon e a fundamentação da ciência como tecnologia. 2. ed. Belo Horizonte: Editora UFMG, 2010.

ROSSI, Paolo. El Científico. In: VILLARI, R. (et al.). El hombre Barroco. Madrid: LAS Editorial, 1991.

Os filósofos e as máquinas, 1400-1700. São Paulo: Companhia das Letras, 1989.

RUGIU, Antonio S. Nostalgia do Mestre Artesão. Campinas/SP: Autores Associados, 1998.

SEPULVEDA, Luís D. O ensino secundário, o liceu de Curitiba e o ensino de Física na província do Paraná (1858-1906). Dissertação [Mestrado]. São Paulo: Pontifícia Universidade Católica, 2002.

\section{Sobre os autores:}

Eliane Mimesse: Doutora em Educação: História da Educação, pela Pontifícia Universidade Católica de São Paulo. Mestre em Educação pela mesma Universidade. Professora Adjunta na Faculdade de Ciências Humanas, Letras e Artes da Universidade Tuiuti do Paraná.

E-mail: emimesse@bol.com.br

Luís Dário Sepúlveda: Mestre em Educação pela Pontifícia Universidade Católica de São Paulo. Licenciado em Física pela Universidade Federal do Paraná e em Matemática pela Pontifícia Universidade Católica do Paraná. Coordenador da área de Química e Física no Colégio Marista Santa Maria de Curitiba. E-mail: dumgh@ig.com.br 
